Indo. J. Chem. Res., 2018, 5(2), 63-68

\title{
IMOBILISASI ASAM HUMAT PADA KITIN DAN APLIKASINYA SEBAGAI ADSORBEN Cr(III)
}

\section{The Immobilization of Humic Acid on Chitin and Its Application as Adsorbent of $\mathrm{Cr}$ (III)}

\author{
Muhamad Sehol ${ }^{*}$, Sri Juari Santosa ${ }^{2}$, Dwi Siswanta ${ }^{2}$ \\ ${ }^{1}$ Program of Biology Education, Teacher and Education Faculty, Iqra University, \\ District of Buru-Maluku - Indonesia \\ ${ }^{2}$ Department of Chemistry, Faculty Mathematics and Natural Science, Universitas Gadjah Mada- \\ Yogyakarta - Indonesia \\ *Corresponding author,e-mail:lasehol@gmail.com
}

Received: Dec. 2017 Published: Jan. 2018

\begin{abstract}
The immobilization of humic acid on chitin has been conducted and applied to the adsorption of $\mathrm{Cr}$ (III). The immobilization of humic acid on chitin has been successfully done by reacting chitin solution in $\mathrm{HCl} 0.5 \mathrm{M}$ and humic acid solution in $\mathrm{NaOH} 0.1 \mathrm{M}$. The humic acid on adsorbent $\mathrm{A}$ and adsorbent $\mathrm{B}$ obtained was stable up to $\mathrm{pH}$ 11. Adsorption of $\mathrm{Cr}(\mathrm{III})$ was maximum at $\mathrm{pH} 5$, with rate of constants was in the orde of chitin II>adsorbent $\mathrm{B}>$ adsorbent $\mathrm{A}>$ chitin $\mathrm{I}$, there are $0.3509 ; 0.2488 ; 0.1553 ; 0.0568$ minute $^{-1}$ respectively. The capacity of adsorption was in the orde of chitin I $>$ adsorbent $\mathrm{B}>$ chitin II $>$ adsorbent A, there are 944.77; 912.53; 895.37; $893.81 \mathrm{mg} / \mathrm{g}$ respectively. The energy of adsorption of $\mathrm{Cr}$ (III) was in orde of chitin II $>$ chitin I $>$ adsorbent A >adsorbent B, there are 22.932; 20.945; 20.312; $19.615 \mathrm{~kJ} / \mathrm{mol}$ respectively. Sequential extraction showed that the adsorption of $\mathrm{Cr}(\mathrm{III})$ was dominated by chemical adsorption with the role of chitin on adsorbent $\mathrm{A}$ and adsorbent B was much higher in adsorbing Cr(III). On adsorbent A, the adsorbed $\mathrm{Cr}(\mathrm{III})$ was $50.84 \mathrm{mg} / \mathrm{g}$ chitin and $1.1 \mathrm{mg} / \mathrm{g}$ humic acid. The similar result was also observed for adsorbent B there are $20.40 \mathrm{mg} \mathrm{Cr}$ (III)/g chitin and $0.80 \mathrm{mg} \mathrm{Cr}(\mathrm{III}) / \mathrm{g}$ humic acid.
\end{abstract}

Keywords: Immobilization, humic acid, chitin, adsorption, $\mathrm{Cr}(\mathrm{III})$

\section{PENDAHULUAN}

Ilmu dan tekhnologi yang berkembang dengan pesat dapat memberikan dampak yang sangat positif bagi kesejahteraan manusia, namun di lain segi ternyata menghasilkan juga dampak yang negatif berupa pencemaran lingkungan dari limbah industri dan aktivitas manusia lainnya. Menurut Palar (1994), salah satu sumber pencemaran yang dihasilkan adalah masuknya logam ke dalam lingkungan terutama tanah dan air secara berlebihan yang akibat buruknya telah banyak dilaporkan misalnya, penyakit mengerikan yang menyerang manusia dan hewan di teluk Minamata, Jepang, akibat keberadaan Merkuri yang berlebihan dalam perairan di teluk tersebut, serta penyakit itai-itai di Jepang akibat keberadaan logam kadmium yang berlebihan dalam perairan.

Krom (Cr) merupakan salah satu jenis logam berat yang dapat mencemari lingkungan, dan jika terakumulasi dalam tubuh dapat menimbulkan masalah yang serius, yaitu dapat menimbulkan berbagai penyakit seperti : sakit kepala, kulit bernanah, serta kanker paru-paru (Shofiyani, 2001).

Berbagai usaha untuk menurunkan konsentrasi logam berat dalam perairan telah dilakukan. Beberapa metode telah dikembangkan untuk menghilangkan logam-logam berat dari air buangan, seperti pengendapan secara kimia, koagulasi, kompleksasi, ekstraksi pelarut, separasi dengan membran, pertukaran ion dan adsorpsi. Dari berbagai teknik tersebut, adsorpsi sering digunakan karena prosesnya yang relatif sederhana dan biaya yang dibutuhkan relatif tidak tinggi.

Senyawa humat dan kitin merupakan dua jenis senyawa yang sering digunakan sebagai adsorben terhadap polutan logam di perairan, dan akhir-akhir ini keduanya sering mengalami modifikasi dalam rangka untuk meningkatkan daya adsorpsinya. Bahan humat keberadaannya tersebar luas di lingkungan, dan untuk 
memperolehnya sangat mudah, karena ada di semua tanah, perairan dan sedimen (Gaffney dkk, 1996). Sedangkan kitin umumnya diperoleh dari cangkang kepiting atau udang dan merupakan senyawa penyusun utama diding sel fungi atau kulit keras krustasea serta merupakan polimer dengan kelimpahan terbesar kedua di alam setelah sellulosa. Baik humat maupun kitin, keduanya memilki gugus-gugus fungsional pada permukaan padatannya dengan daya adsorpsi yang tinggi terhadap polutan-polutan logam di perairan. Hal ini disebabkan oleh adanya gugusgugus fungsional utama seperti $-\mathrm{OH}$, $-\mathrm{COOH}$, - $\mathrm{CO}$, dan -NHCO- masing-masing pada senyawa humat dan kitin (No dkk, 1989).

Asam humat merupakan senyawa humat yang tidak larut dalam air pada kondisi asam tetapi larut pada kondisi $\mathrm{pH}$ alkalis. Menurut hasil penelitian Alimin (2000) dan Sudiono (2001) pada $\mathrm{pH}$ di atas 2 asam humat sudah mulai larut dan pada $\mathrm{pH} 6$ asam humat praktis telah larut semua. Sedangkan, di satu sisi senyawa kitin tidak dapat larut dalam kondisi $\mathrm{pH}$ asam ataupun $\mathrm{pH}$ alkalis.

Adanya fenomena pengaruh kelarutan asam humat oleh $\mathrm{pH}$, maka beberapa peneliti berusaha untuk menurunkan kelarutan asam humat pada $\mathrm{pH}$ tinggi. Impregnasi asam humat pada silika gel telah dilakukan oleh Sujandi (2002) dan dihasilkan adanya asam humat yang stabil hingga $\mathrm{pH}$ 8. Usaha yang sama telah dilakukan dengan cara imobilisasi asam humat pada permukaan silika gel oleh Koopal yang dikembangkan oleh Artech, Inc melalui crosslinking dan imobilisasi, sehingga didapatkan kelarutan asam humat yang sangat rendah sampai pH 12 (Sanjaya dkk, 1999). Selain itu, Irawati (2004) telah melakukan imobilisasi asam humat pada kitosan dan didapatkan kelarutan asam humat yang menurun sampai $\mathrm{pH}$ 11,55.

Adanya kenyataan bahwa, salah satu sifat karakteristik asam humat menurut Stevenson (1994) adalah kemampuannya untuk berinteraksi dengan ion-ion logam, oksida, hidroksida, mineral-mineral dan bahan organik, termasuk polutan-polutan toksik lainnya untuk membentuk persenyawaan yang larut maupun yang tidak larut dalam air, serta adanya dukungan hasil penelitian yang telah disebutkan di atas, maka dengan adanya hasil isolasi dan pengidentifikasian gugus-gugus kitin maupun asam humat diharapkan dapat dilakukan perbaikan metode untuk lebih meningkatkan daya adsorpsinya masing-masing melalui imobilisasi asam humat pada senyawa organik kitin dengan memanfaatkan gugus-gugus kimianya untuk berinteraksi.

Tujuan dari penelitian ini adalah mengimobilisasikan asam humat pada senyawa kitin dengan harapan dapat memperbaiki daya adsorpsinya dan menurunkan kelarutan asam humat pada $\mathrm{pH}$ tinggi, serta mempelajari dan menentukan laju reaksi, kapasitas, dan energi adsorpsi dalam aplikasinya sebagai adsorben $\mathrm{Cr}(\mathrm{III})$.

\section{METODOLOGI}

\section{Isolasi dan pemurnian asam humat dari tanah gambut Ambarawa-Jateng}

Bahan tanah gambut yang diperoleh dari Ambarawa Jawa Tengah digunakan untuk mengisolasi asam humat menggunakan pelarut $\mathrm{NaOH}$ 0,1 M (perbandingan tanah dengan pelarut 1:10), sebagaimana proses yang telah dilakukan oleh Stevenson (1994), Alimin (2000), dan Sudiono (2001). Untuk mengetahui keberhasilan isolasi asam humat, asam humat tanpa pemurnian dan asam humat hasil pemurnian yang diperoleh dalam penelitian ini dilakukan dengan cara penetapan kadar abu dan identifikasi secara spektroskopi inframerah.

\section{Isolasi Kitin}

Dalam penelitian ini cangkang kepiting dipreparasi dalam dua tahap perlakuan yaitu: (1) kepiting direbus selama 40 menit hingga 1 jam, selanjutnya daging dipisahkan dari cangkangnya. Cangkang yang diperoleh langsung dikeringkan dalam oven pada suhu $120{ }^{\circ} \mathrm{C}$, (2) dalam keadaan mentah, cangkang kepiting dipisahkan kemudian direndam dalam larutan kaporit teknis (4\%) sambil diaduk selama 30 menit. Selanjutnya cangkang dikeringkan pada suhu udara dengan cara diangin-anginkan.

Cangkang kepiting yang telah dikeringkan berdasarkan kedua proses perlakuan di atas, masing-masing digerus halus dan selanjutnya dilakukan proses isolasi kitin menurut metode yang telah dilakukan oleh No, dkk (1989). Hasil isolasi kitin yang diperoleh dari proses perlakuan pertama selanjutnya disebut kitin I, sedangkan kitin yang diperoleh dari proses perlakuan ke dua disebut kitin II. Gugus-gugus fungsional utama kitin diidentifikasi dengan spektroskopi FT-IR. 


\section{Imobilisasi Asam Humat pada Kitin (Pembuatan Adsorben A dan B)}

Sebanyak 40 gram kitin I diaktivasi dengan $250 \mathrm{ml} \mathrm{HCl} 0,5 \mathrm{M}$ hingga larut, selanjutnya 4 gram asam humat yang telah dilarutkan dalam $500 \mathrm{ml} \mathrm{NaOH} \mathrm{0,5} \mathrm{M} \mathrm{diambil} \mathrm{sebanyak} 250 \mathrm{ml}$ kemudian dicampurkan dengan larutan kitin hasil aktivasi dan diaduk selama 2 malam. Hasil imobilisasi selanjutnya dibilas dengan aquades, lalu dipanaskan pada oven dengan suhu $70{ }^{\circ} \mathrm{C}$ selama 30 menit, kemudian dikeringkan pada temperatur kamar. Adsorben hasil imobilisasi selanjutnya disebut adsorben A. Hal yang sama dilakukan juga untuk mendapatkan adsorben B dengan bahan dasar kitin II sebanyak 30 gram dan asam humat sebanyak 3 gram. Perubahan gugus fungsional ke-dua adsorben diidentifikasi dengan spektroskopi FT-IR.

\section{Penentuan Banyaknya Asam Humat yang Terimobilisasi pada Kitin}

Sebanyak 0,1gram adsorben A dilarutkan dalam aquades, kemudian $\mathrm{pH}$ larutan diatur pada interval 2-12 dengan menggunakan $\mathrm{HNO}_{3}$ untuk $\mathrm{pH}$ asam dan $\mathrm{NaOH}$ untuk $\mathrm{pH}$ basa. Campuran diaduk selama 2 jam kemudian didiamkan semalam dan hasil yang diperoleh disaring. Supernatan yang diperoleh ditentukan kandungan asam humat terlarutnya menggunakan spektrofotometer UV-Vis pada panjang gelombang $400 \mathrm{~nm}$ dengan metode kurva kalibrasi menggunkan larutan standar asam humat $100 \mathrm{ppm}$. Banyaknya asam humat yang terimobilisasi pada kitin dihitung secara tidak langsung berdasarkan kandungan asam humat yang terlarut pada berbagai $\mathrm{pH}$ tersebut. Hal yang sama dilakukan pula pada adsorben B.

\section{Stabilitas Asam Humat Terimobilisasi pada Kitin}

Sebanyak 0,1 gram adsorben A dilarutkan dalam aquades, kemudian $\mathrm{pH}$ larutan diatur pada interval 2-12 dengan menggunakan $\mathrm{HNO}_{3}$ untuk $\mathrm{pH}$ asam dan $\mathrm{NaOH}$ untuk $\mathrm{pH}$ basa. Campuran diaduk selama 2 jam kemudian didiamkan semalam dan hasil yang diperoleh disaring. Supernatan yang diperoleh ditentukan kandungan asam humat terlarutnya menggunakan spektrofotometer UV-Vis pada panjang gelombang $400 \mathrm{~nm}$ dengan kurva standar standar menggunkan larutan standar asam humat $100 \mathrm{ppm}$. Hal yang sama dilakukan pula pada adsorben B.
Interaksi Adsorben dengan $\mathrm{Cr}$ (III) Pengaruh pH terhadap proses adsorpsi logam.

Sebanyak 0,01 gram kitin I, kitin II, adsorben A, dan adsorben B masing-masing direndam dalam $15 \mathrm{~mL}$ larutan $\mathrm{Cr}(\mathrm{III})$ dengan konsentrasi $50 \mathrm{mg} / \mathrm{L}$. Harga $\mathrm{pH}$ larutan divariasikan pada $\mathrm{pH} \mathrm{2,} \mathrm{4,} \mathrm{6,} \mathrm{8,} \mathrm{dan} 10$. Setelah interaksi selama 1 jam, larutan disaring, kemudian konsentrasi logam dalam filtrat diukur secara AAS. Harga pH optimum digunakan sebagai dasar untuk kondisi pengamatan lebih lanjut.

\section{Laju adsorpsi $\mathbf{C r}$ (III) pada setiap adsorben.}

Sebanyak $10 \mathrm{ml}$ larutan $\mathrm{Cr}(\mathrm{III})$ dengan konsentrasi $100 \mathrm{mg} / \mathrm{L}$ diinteraksikan dalam kondisi $\mathrm{pH}$ optimum dengan 0,01 gram kitin I, kitin II, adsorben A, dan adsorben B menggunakan waktu interaksi yang bervariasi, yaitu $0 ; 2 ; 4 ; 10 ; 20 ; 30 ; 60 ; 90$; dan 120 menit. Larutan disaring dan konsentrasi logam yang tersisa dalam filtrat diukur dengan spektroskopi serapan atom. Penentuan konstanta laju adsorpsi $\left(\mathrm{k}_{\mathrm{ads}}\right)$ dan konstanta kesetimbangan adsorpsi $(\mathrm{K})$ diperoleh dengan menerapkan model persamaan kinetika usulan Santosa (2001) yang diturunkan dari persamaan kinetika LangmuirHinshenwold. Persamaan kinetikanya dapat dituliskan : $\ln \left(\mathbf{C}_{\mathbf{o}} / \mathbf{C}_{\mathbf{a}}\right) / \mathbf{C}_{\mathbf{a}}=\mathbf{k}_{\text {ads }} / \mathbf{C}_{\mathbf{a}}+\mathbf{K}(\mathbf{1})$.

\section{Penetapan energi dan kapasitas adsorpsi Cr(III) pada setiap adsorben.}

Sebanyak 0,01 gram kitin I, kitin II, adsorben A, dan adsorben B, masing-masing diinteraksikan dengan larutan $\mathrm{Cr}(\mathrm{III})$ sebanyak $10 \mathrm{~mL}$ pada kondisi pH optimum. Konsentrasi untuk setiap larutan divariasikan dari 50; 100; 150; 200; 250; 300; 500; dan 1000 mg/L. Setelah diinteraksikan selama 24 jam, larutan disaring. Filtratnya dianalisis dengan metode AAS untuk mengetahui jumlah logam yang tersisa dalam larutan. Penentuan kapasitas adsorpsi (b), konstanta kesetimbangan $(\mathrm{K})$, dan energi adsorpsi (E) diperoleh dengan menggunakan persamaan isoterm Langmuir: $\mathbf{C}_{\mathbf{a}} / \mathbf{m}=\mathbf{1} / \mathbf{b K}+$ $\mathrm{C}_{\mathrm{a}} / \mathrm{b}$ (2). 


\section{HASIL DAN PEMBAHASAN}

\section{Identifikasi Spektra FT-IR Asam Humat dan Kitin Hasil Isolasi}

Hasil identifikasi spektra FT-IR asam humat sebelum dan sesudah pemurnian menunjukkan pita serapan utama yang cenderung sama pada daerah $3398,3 \mathrm{~cm}^{-1}$ (vibrasi $-\mathrm{OH}$ ), 2925,8 $\mathrm{cm}^{-1}$ (-C-H alifatik), 1616,2;1508,2; $1541 \mathrm{~cm}^{-1}$ (-C=C- aromatic), 1215,5 $\mathrm{cm}^{-1}$ (-C-O), dan pita serapan dengan bilangan gelombang di sekitar 1700-an $(\mathrm{C}=\mathrm{O})$. Pada asam humat murni menghasilkan spektra dengan intensitas yang lebih tajam sebagai tanda hilangnya pengotor.
Kemungkinan reaksi yang ada dalam proses imobilisasi adalah:

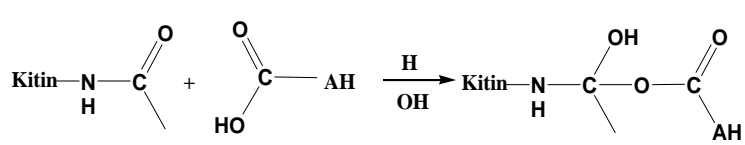

Jumlah dan stabilitas asam humat pada adsorben ditunjukkan pada Gambar 1. Terlihat bahwa jumlah asam humat pada adsorben $\mathrm{A}$ dan B, masing-masing berkisar sebesar 9,25\% dan $1,64 \%$ dan dapat stabil hingga $\mathrm{pH} 11$.

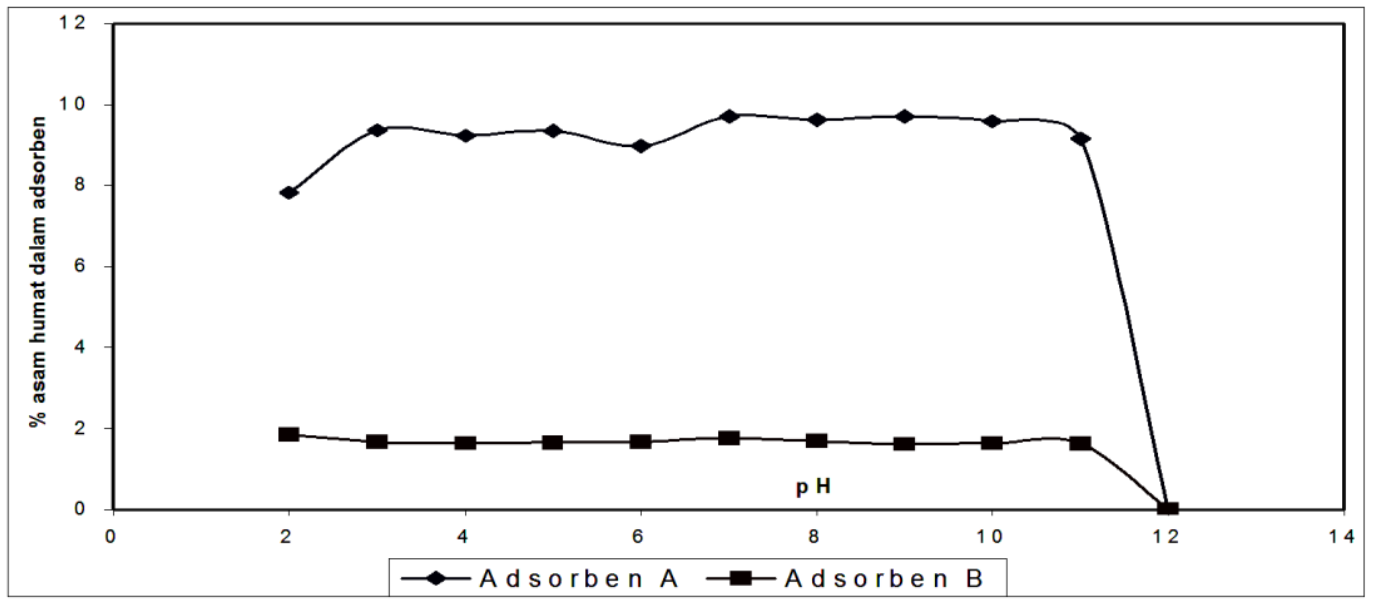

Gambar 1 Jumlah dan stabilitas asam humat pada adsorben A dan B

Hasil kajian menunjukkan gugus $-\mathrm{COOH}$ terdapat sebagai gugus dominan pada asam humat.

Spektra FT-IR kitin I dan kitin II menunjukkan hasil yang juga cenderung sama, namun kitin II menghasilkan spektra dengan intensitas yang lebih baik akibat pengaruh pencucian dengan larutan kaporit yang mampu menghilangkan pengotor organik kitin. Pita serapan utamanya muncul pada $3442,7 \mathrm{~cm}^{-1}$ (vibrasi $-\mathrm{OH}), 2854,5 \mathrm{~cm}^{-1} \quad(\mathrm{C}-\mathrm{H}$ alifatik), $1431,1 \mathrm{~cm}^{-1}$ (-NH-), dan $1624 \mathrm{~cm}^{-1}(\mathrm{C}=\mathrm{O})$. Hasil ini menunjukkan bahwa gugus amida (-NHCO-) merupakan gugus utama yang terdapat pada kitin.

Setelah asam humat diimobilisasikan pada kitin didapatkan dua jenis adsorben (adsorben A dan B) dan mengalami perubahan spektra FT-IR bila dibandingkan dengan spektra FT-IR kitin, yaitu: pita serapan $1541 \mathrm{~cm}^{-1}$ dan $1654,8 \mathrm{~cm}^{-1}$ mengklarifikasi adanya asam humat dalam adsorben, sedangkan pita serapan 1157,2 $\mathrm{cm}^{-1}$ mengklarifikasi munculnya gugus baru -C-O-C-.

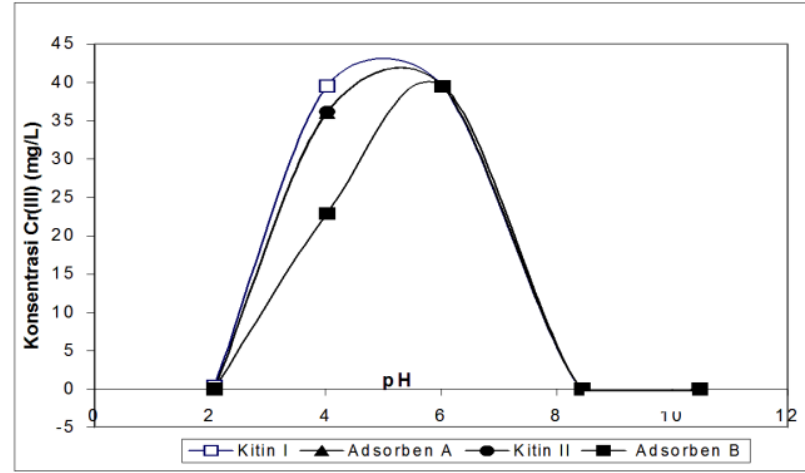

Gambar 2 Pengaruh pH terhadap adsorpsi $\mathrm{Cr}$ (III) pada kitin dan adsorben

\section{Pengaruh pH terhadap adsorpsi $\mathrm{Cr}$ (III)}

Gambar 2 memperlihatkan pengaruh $\mathrm{pH}$ terhadap adsorpsi $\mathrm{Cr}(\mathrm{III})$ oleh kitin I, kitin II, adsorben A, dan adsorben $\mathrm{B}$. Pada $\mathrm{pH}$ rendah terjadi adsorpsi $\mathrm{Cr}(\mathrm{III})$ dalam jumlah sedikit akibat adanya kompetisi $\mathrm{Cr}(\mathrm{III})$ dengan $\mathrm{H}^{+}$yang konsentrasinya tinggi pada $\mathrm{pH}$ rendah, selanjutnya mengalami peningkatan seiring kenaikan $\mathrm{pH}$ sehingga tercapai adsorpsi maksimum ( $\mathrm{pH}$ optimum) pada $\mathrm{pH}$ 5-6. Pada 


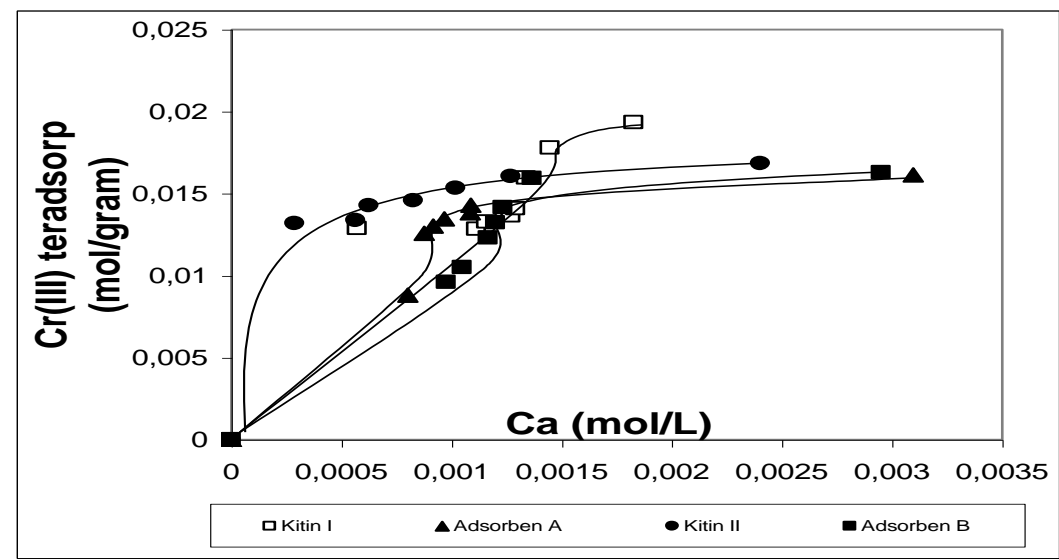

Gambar 3 Isoterm Langmuir adsorpsi Cr(III) pada adsorben

$\mathrm{pH}>6$ semakin mengalami penurunan adsorpsi karena harga $\mathrm{Ksp} \mathrm{Cr}(\mathrm{OH})_{3}$ terlampaui sehingga membentuk endapan $\mathrm{Cr}(\mathrm{III})$ hidroksida.

\section{Penentuan Laju Reaksi Adsorpsi Cr(III) pada Setiap Adsorben}

Berdasarkan persamaan (1), maka dengan membuat kurva linear $\ln \left(\mathrm{C}_{\mathrm{o}} / \mathrm{C}_{\mathrm{a}}\right) / \mathrm{C}_{\mathrm{a}}$ vs $\mathrm{t} / \mathrm{C}_{\mathrm{a}}$ dapat ditentukan harga konstanta laju adsorpsi $\left(\mathrm{k}_{\mathrm{ads}}\right)$ dan konstanta kesetimbangan adsorpsi $(\mathrm{K})$ masing-masing dari intersep dan slope kurva linear yang didapat. Dalam penelitian ini, besarnya harga $\mathrm{k}_{\mathrm{ad}}$ dan $\mathrm{K}$ kitin maupun adsorben diperlihatkan pada Table 1. Terdapat kecenderungan bahwa $\mathrm{k}_{\mathrm{ads}}$ kitin II dan adsorben B lebih besar daripada kitin I dan adsorben A sebagai akibat dari tidak terhalanginya proses adsorpsi $\mathrm{Cr}$ (III) oleh pengotor-pengotor organik yang telah dihilangkan oleh pencucian dengan larutan kaporit pada saat proses isolasi kitinnya.

\section{Penetapan Energi dan Kapasitas Adsorpsi Cr(III) pada Setiap Adsorben.}

Perhitungan kapasitas dan energi adsorpsi Cr(III) pada kitin I, kitin II, adsorben A, dan adsorben $\mathrm{B}$ adalah berdasarkan model isoterm Langmuir menurut persamaan : $\mathbf{C}_{\mathbf{a}} / \mathbf{m}=\mathbf{1} / \mathbf{b K}+$ $\mathbf{C}_{\mathbf{a}} / \mathbf{b}$ (2), di mana $\mathrm{C}_{\mathrm{a}}$ adalah konsentrasi ion logam saat adsorpsi diperoleh dari intersep dan slope. Nilai K yang diperoleh digunakan untuk menentukan harga energi adsorpsi yang dihitung menurut persamaan: $\mathbf{E}=\mathbf{R T} \ln \mathbf{K}$ (3).

Berdasarkan asumsi ini, maka Tabel 2 memperlihatkan besarnya energi dan kapasitas adsorpsi yang diperoleh dari hasil interaksi $\mathrm{Cr}$ (III) dengan kitin dan adsorben. Gambar 3 menunjukkan pola adsorpsi yang semakin naik dari konsentrasi awal dan mengalami kesetimbangan pada konsentrasi tertentu. Gambaran ini mengindikasikan terjadinya pola adsorpsi isoterm Langmuir yang juga diperkuat oleh harga R dalam Tabel 2.

Tabel 1 Konstanta laju adsorpsi $\left(\mathrm{k}_{\mathrm{ads}}\right)$ dan konstanta kesetimbangan adsorpsi (K) kitin dan Adsorben

\begin{tabular}{ccc}
\hline \multirow{2}{*}{ Adsorben } & \multicolumn{2}{c}{ Parameter } \\
\cline { 2 - 3 } & $\mathbf{k}_{\text {ads }}\left(\mathbf{m e n i t}^{-1}\right)$ & $\mathbf{K}(\mathbf{m o l} / \mathbf{L})^{-1}$ \\
\hline Kitin I & 0,0568 & 68167 \\
Adsorben A & 0,1553 & 104 \\
Kitin II & 0,3509 & 1958 \\
Adsorben B & 0,2488 & 942 \\
\hline
\end{tabular}

Tabel 2 Parameter isoterm Langmuir kitin dan adsorben yang diinteraksikan dengan $\mathrm{Cr}$ (III)

\begin{tabular}{lcllll}
\hline \multicolumn{1}{c}{ Adsorben } & $\mathbf{R}^{2}$ & $\mathbf{K}(\mathbf{m o l} / \mathbf{L})^{-1}$ & $\mathbf{b}(\mathbf{m o l} / \mathbf{g r a m})$ & $\mathbf{E}(\mathbf{k J} / \mathbf{m o l})$ \\
\hline Kitin I & 0,94 & 4438 & $1,817 \times 10^{-2}$ & 20,946 \\
Adsorben A & 0,86 & 3442 & $1,719 \times 10^{-2}$ & 20,312 \\
Kitin II & 0,90 & 9840 & $1,722 \times 10^{-2}$ & 22,932 \\
Adsorben B & 0,99 & 2602 & $1,755 \times 10^{-2}$ & 19,615 \\
\hline
\end{tabular}

Data pada Gambar 3 merupakan data yang digunakan sebagai acuan dalam pembuatan kurva $\mathrm{C}_{\mathrm{a}} / \mathrm{m}$ vs $\mathrm{C}_{\mathrm{a}}$ sehingga nilai $\mathrm{b}, \mathrm{K}$, dan $\mathrm{E}$ yang tercantum pada Tabel 2 dapat diketahui. Dari Tabel 2 terlihat bahwa energi yang dihasilkan pada proses adsorpsi berkisar 19,165-22,932 $\mathrm{kJ} / \mathrm{mol}$ dengan kapasitas adsorpsi kitin I yang lebih besar bila dibandingkan dengan kitin II, adsorben A, dan adsorben B.

\section{KESIMPULAN}

Berdasarkan hasil kajian di atas, maka dapat ditarik kesimpulan:

1. Asam humat dapat diimobilisasikan pada kitin dan mampu stabil hingga $\mathrm{pH} 11$

2. Adsorpsi $\mathrm{Cr}$ (III) pada adsorben maksimum pada $\mathrm{pH}$ 5-6, dengan konstanta laju sesuai urutan kitin II >adsorben $\mathrm{B}>$ adsorben A>kitin I yang besarnya masing-masing 0,$3509 ; 0,2488 ; 0,1553 ; 0,0568$ menit $^{-1}$ 
3. Kapasitas adsorpsi sesuai dengan urutan kitin I > adsorben B> kitin II > adsorben A yang besarnya masing-masing adalah 1,817 x $10^{-2} ; 1,755 \times 10^{-2} ; 1,722 \times 10^{-2} ; 1$, $719 \times 10^{-2} \mathrm{~mol} / \mathrm{g}$.

4. Energi adsorpsi $\mathrm{Cr}(\mathrm{III})$ pada kitin dan adsorben mengikuti urutan kitin II $>$ kitin I>adsorben A>adsorben B masing-masing sebesar 22,$932 ; 20,946 ; 20,312 ; 19,615$ $\mathrm{kJ} / \mathrm{mol}$.

\section{DAFTAR PUSTAKA}

Alimin, 2000, Fraksinasi Asam Humat dan Pengaruhnya pada Kelarutan Ion $\mathrm{Zn}^{2+}$, $\mathrm{Cd}^{2+}, \mathrm{Mg}^{2+}$, dan $\mathrm{Ca}^{2+}$, Tesis, Kimia FMIPA, Universitas Gadjah Mada, Yogyakarta.

Gaffney, J.S., Marley, N.A., dan Clack, S.B., 1966, Humic and Fulvic Acid : Isolation, Structure and Environmental Role, American Chemical Society, Washington, DC.

Irawati, U., 2004, Immobilisasi Asam Humat pada Kitosan dan Aplikasinya sebagai Adsorben Cd (II), Skripsi, Kimia FMIPA, Universitas Gadjah Mada, Yogyakarta.

No, H., Meyers, S.P., Lee, K.S., 1989, Isolation and Characterization of Chitin From Crawfish Shell Waste, J. Agric. Food. Chem., 27, 575-579.

Palar, H., 1994, Pencemaran dan Toksikologi Logam Berat, Rineka Cipta, Jakarta
Sanjaya, H.G., Fataftah, A.K., Walia, D.S., dan Srivastava, K. C., 1999, Humasorp - $C S^{T M}$ : A Humic Acid - Based Adsorbent to Remove Organic and Inorganic Contaminant, (dalam Ghabbour, E.A., dan Davie, G.), Properties and Applications, The Royal Society of Chemistry, Cambridge.

Santosa, S.J., 2001, Single and Competitive Adsorption Kinetics of $\mathrm{Cd}(\mathrm{II})$ and $\mathrm{Cr}$ (III) by Humic Acid, Prosiding Seminar Nasional Kimia Anorganik, Universitas Gadjah Mada, Yogyakarta.

Shofiyani, A., 2001, Studi Adsorpsi Cr(III) dan Cr(VI) pada Kitosan dan Kitosan Sulfat dari Cangkang Udang Windu (Phenaus monodon), Tesis, Universitas Gadjah Mada, Yogyakarta.

Stevenson, F.J., 1994, Humus Chemistry: Genesis, Compositions, Reactions, $2^{\text {nd }}$. Ed., John W iley \& Sons, Inc., New York

Sudiono, S., 2001, Sifat Asam Basa Asam Humat dan Interaksinya dengan Logam Kromium (III), Tembaga (II), Kobalt(II) dan Nikel (II), Tesis, Kimia FMIPA, Universitas Gajah Mada, Yogyakarta.

Sujandi, 2002, Impregnasi Asam Humat pada Silika Gel dan Aplikasinya untuk Adsorpsi Tembaga (II), dan Kalsium (II), Skripsi Kimis FMIPA, Universitas Gajah Mada, Yogyakarta. 